Int. J. Electrochem. Sci., 14 (2019) $238-249$

\title{
Electrode materials based on Micro-emulsion Polymerized Polyaniline and Their Capacitive Property
}

\author{
Lijun Ren*, Gaini Zhang, Huiqin Li, Dengwei Hu, Shumei Dou \\ College of Chemistry and Chemical Engineering, Engineering Research Center of Advanced \\ Ferroelectric Functional Materials, Key Laboratory of Phytochemistry, Baoji University of Arts and \\ Sciences, Baoji, 721013, P. R. China \\ *E-mail: renlijun.wind@163.com
}

doi: $10.20964 / 2019.01 .10$

Received: 14 September 2018 / Accepted: 22 October 2018 / Published: 30 November 2018

\begin{abstract}
The conductive polyaniline (PANI) electrode materials with different morphologies were prepared by micro-emulsion polymerization with dodecylbenzene sulfonic acid (DBSA) as the dopant and surfactant, and ammonium persulfate (APS) as the oxidant. The concentration of DBSA was crucial in tailoring the morphology of PANI. Electrochemical tests showed that the capacitive properties of the electrode materials were influenced markedly by their morphologies and conductivities. At low DBSA concentration, the obtained PANI nanoribbon (PANI-1) electrode processed high specific capacitance $\left(573 \mathrm{~F} \mathrm{~g} \mathrm{~g}^{-1}\right.$ at a current density of $0.2 \mathrm{~A} \mathrm{~g}^{-1}$ ) and excellent rate performance (78\% capacitance retention from 0.2 to $10 \mathrm{~A} \mathrm{~g}^{-1}$ ) but showed poor cycling stability. Furthermore, the specific capacitance and rate performance of the resultant PANI electrodes were decreased with increase in the concentration of DBSA. At high DBSA concentration, the specific capacitance and rate performance of the obtained PANI nanoparticle (PANI-4) electrode decreased to $205 \mathrm{~F} \mathrm{~g}^{-1}\left(0.2 \mathrm{~A} \mathrm{~g}^{-1}\right.$ ) and $63 \%$ (from 0.2 to $10 \mathrm{~A} \mathrm{~g}^{-}$ $\left.{ }^{1}\right)$, respectively. Nevertheless, it possessed superior cycling stability with just $8 \%$ capacitance loss after 2000 charging/discharging cycles.
\end{abstract}

Keywords: Polyaniline; Dodecylbenzene sulfonic acid; Micro-emulsion polymerization; Electrode material; Supercapacitor

\section{FULL TEXT}

(C) 2019 The Authors. Published by ESG (www.electrochemsci.org). This article is an open access article distributed under the terms and conditions of the Creative Commons Attribution license (http://creativecommons.org/licenses/by/4.0/). 